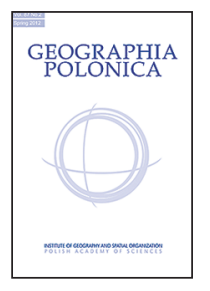

\title{
Geographia Polonica
}

2016, Volume 89, Issue 1, pp. 113-115 \\ INSTITUTE OF GEOGRAPHY AND SPATIAL ORGANIZATION \\ POLISH ACADEMY OF SCIENCES \\ www.igipz.pan.pl \\ www.geographiapolonica.pl
}

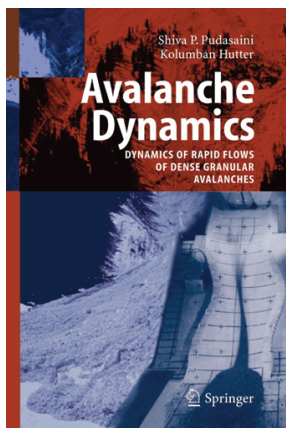

Pudasaini S.P. \& Hutter K., 2007

Avalanche dynamics:

Dynamics of rapid flows of dense granular avalanches

Berlin-Heidelberg: Springer Science \& Business Media

Hardcover, 614 pages, 222 figures, 12 tables

ISBN: 13 978-3-540-32686-1

\section{Reviewed by Ryszard J. Kaczka}

Faculty of Earth Sciences, University of Silesia in Katowice

Będzińska 60, 41-200 Sosnowiec: Poland

e-mail: ryszard.kaczka@us.edu.pl

The book published in 2007 aimed at describing the use of mathematical tools to model and predict snow avalanche movements in a real terrain rather than in the controlled environment of a laboratory. The authors are established scientists working with physical-mathematical modelling of threedimensional free flows. Shiva P. Pudasaini holds a position at the University of Bonn, Faculty of Mathematical and Natural sciences, whereas Kolumban Hutter is a professor at the Swiss Federal Institute of Technology. Their published works give evidence that the quantitative description of physical processes is their expertise.

As the authors emphasise, the book is the result of their teaching experience. This is one of the classical models of writing motivation in academic circles. The chain of the lectures presented to students on various level of education and institution has created a demand for a textbook. The content of the book is divided into five parts. The first one introduces the reader to a wider perception of the snow avalanche as the phenomena influencing present and past human activities. Pudasaini and Hutter stress the necessity for the investigation of the snow avalanche, and present a short history of the studies. Almost all of the examples of the biggest snow avalanche disasters come from Western Europe, mainly the Alps, and Nord America. This suggests that little is known about that kind of natural hazard in other parts of the world. The authors try to call the readers' attention to the fact that the snow avalanche is not always a natural threat. During the World War II, the avalanches were weaponised and up to 80,000 soldiers were killed as a result of purposely provoked 
avalanche events (Fraser 1978). Part II and III are focused on a continuum mechanical theory for dense avalanches sliding down non-trivial topographies, and a shock created during the movement. Herein, there is comprised a detailed presentation of the evolution of the models describing both the mechanism and forces governing the movements of the majority of types of granular masses, and specifically snow avalanches. Also, the Savage-Hutter model (SH model or SH theory) is explained in detail here. Particularly interesting is a fragment, which discusses the evolution from $1 \mathrm{D}$ to $3 \mathrm{D}$ model and the incorporation of the topography to the model. These as well as the implication of the flow within the channel of different dimensions and shapes make the theoretical model capable of representing real events. In this part, the authors also discuss the features of the most avalanche abounded regions in the world, i.e. the geographical location, steepness, elevation, orientation, shape of the terrain, roughness of the ground, snowpack and weather conditions. This coupling of mathematical and physical knowledge and analyses of the mountain environment is one of the chief attributes of the book. The following part focuses on testing and validation of theoretical prediction with the employment of different measuring techniques and field examples from real locations. Various experiments are described, including the employment of the laboratory avalanche chute with real-time recordings, wind tunnel allowing the use of the particle image velocity technique etc.

The final part of the book raises the question of how to build systems of the avalanche protection and defense structure by means of an efficient implementation of the theoretical and practical expertise. The authors walk us through the history of the human efforts to protect their lives and properties against avalanches, and present recent state-of-theart solutions in different regions of the world.

One of the main conclusions of the book is that in spite of all the achievements (advanced technology and mathematical models), we are still at the beginning of the journey leading to the understanding of all the mechanisms governing the initiation, movement and character of snow avalanches.

As the authors declare, the book is dedicated to geologists and civil engineers. Interestingly, geomorphologists or geographers are not mentioned as potential readers. This has brought up an interesting question - is the mathematical modelling of the processes shaping the environment too challenging for our part of the scientific community? There is no simple answer to such an intriguing question. Reading of the book requires a mathematical and physical background, which typically is not provided by most of the departments of geography. However, can we afford to neglect such opportunities for research, and do we really do that?

The principles of the Savage-Hutter model/ theory, published in 1989 and still discussed (Hutter et al. 2005), provide an excellent tool to investigate and quantitatively describe the movement of the mass of granual material, and produce numerical predictions. This includes not only snow avalanches but basically the majority of types of mass movements: complex landslides, debris flows, mud flows, pyroclastic flows (e.g. lahars), turbity currents, which are underwater avalanches. This theoretical model was tested and verified with lab experiments. The field implementation of the model was successfully tested by researches of various fields.

This brings us back to the question of the usefulness of such techniques for physical geographers, and also to the transition of the knowledge from the virtual to real world. One of the most popular ways of the snow avalanche modelling is performed with the use of AVAL (Christen et al. 2002) and RAMMs (Christen et al 2010) software, both developed in SLF Institute for Snow and Avalanche Research, being a part of the Swiss Federal Institute for Forest, Snow and Landscape Research. Although the main principle of the 1D and 2D modelling is based on VoellmySalm model, Savage-Huttertheory is implemented and use the defined properties of the shallow free surface flows. Both programs 
are widely employed to investigate snow avalanches, RAMMs as well as debris flows. This is not limited to a small group of experts equipped with mathematical skills and a profound understanding of physics. On the contrary, the software is designed to serve as a tool for everybody interested in avalanches and a rapid fluid-like slope movement. Nevertheless, the understanding of the results requires a basic understanding of the

\section{References}

Christen M., Bartelt P., Gruber U., 2002. AVAl-1D: An avalanche dynamics program for the practice [in:] International Congress Interpraevent 2002 in the Pacific Rim - Matsumoto, Japan, Congress publication, vol. 2, pp. 715-725.

Christen M., Kowalski J., Bartelt P., 2010. RAMMS: Numerical simulation of dense snow avalanches in three-dimensional terrain. Cold Regions Science and Technology, vol. 63, no. 1, pp. 1-14.

Fraser C., 1978. Avalanches and snow safety. New York: Scribner.

Hutter K., Savage S.B., Nohguchi Y., 1989. Numerical, analytical, and laboratory expe- mathematics and physics behind the computations. The book has considerable merits. Firstly, because it provides the reader with an abundance of theoretical information. Secondly, because almost all of the information is linked to practical examples and put into a local context, which makes a very good combination of the theoretical bases and illustrations from real life.

rimental studies of granular avalanche flows. Annals of Glaciology, 13, pp. 109-116.

Hutter K., Wang Y., Pudasaini S.P., 2005. The Savage-Hutter avalanche model: How far can it be pushed? Philosophical Transactions of the Royal Society of London A: Mathematical, Physical and Engineering Sciences, vol. 363, no. 1832, pp. 1507-1528.

Schneider D., Allen S., Christen M., Huggel C., McArdell B., Bartelt P., 2008. Application of the RAMMS model to recent and potential rock-ice avalanches in the Mount Cook region (New Zealand). Geophysical Research Abstracts, vol. 10.
(C) Ryszard J. Kaczka

(C) Geographia Polonica

(C) Institute of Geography and Spatial Organization

Polish Academy of Sciences - Warsaw • 2016
Review first received • February 2016

Review accepted • February 2016 
http://rcin.org.pl 